Lost IUD penetrating bladder wall

Thanks to Vural and colleagues who reported their interesting case of a misplaced intrauterine device (IUD). ${ }^{1}$ I would like to mention some points in relation to their letter.

With the increased uptake of intrauterine methods ${ }^{2}$ and the majority of uterine perforations said to occur at the time of device insertion (but go undetected), 3 uterine perforation is more frequent than Vural et al. ${ }^{1}$ suggest.

Uterine perforation is now undiagnosed at the time of IUD insertion procedure, also because patients are asymptomatic despite this complication having occurred. There is currently greater use of analgesia prior to as well as local anaesthetic (including injectable) during IUD insertion procedures than before.

To facilitate early diagnosis of uterine perforation, especially in the absence of symptoms, clinicians should have a low threshold for performing, or referring for, pelvic ultrasonography. Instances of difficult insertion, insertion after difficult removal, where uterine sounding measurements are much different from the previous of a patient's (especially after a difficult removal of an old device), and no visible threads at routine follow up post-IUD insertion are examples.

Unfortunately most services where IUD fitting procedures take place are not equipped with ultrasound scanners. Where there is local access to ultrasound or a referral has to be made, appointment waiting times tend to cause a delay in diagnosis of uterine perforation. Similarly, an appointment for laparascopic removal of a misplaced device could be a few months. However, initial counselling on intrauterine methods ${ }^{4}$ to include information about the small risk of uterine perforation and its management will be helpful to patients interested in this highly effective method of contraception.

Hannat Akintomide, MBBS, DFSRH

Staff Grade Doctor, Camden Contraceptive

Services, London, UK.

E-mail:h.akintomide@nhs.net

References
Vural M, Toy H, Camuzcuoglu H, Sezgin B. Lost IUD penetrating bladder wall [Letter]. J Fam Plann Reprod Health Care 2010; 36: 182

2 The Health and Social Care Information Centre, Lifestyle Statistics, 2009. NHS Contraceptive Services England 2008/09 http://www.ic.nhs.uk/webfiles/ publications/nhscontra0809/Contraception Report 20 082009 Version 2.pdf [Accessed 18 August 2010]. Harrison-Woolrych M, Ashton J, Coulter D. Uterine perforation on intrauterine device insertion: is the incidence higher than previously reported? Contraception 2003; 67: 53-56.

4 Faculty of Sexual and Reproductive Healthcare Clinical Effectiveness Unit. FSRH Guidance (November 2007). Intrauterine Contraception. http://www.fsrh.org/admin/ uploads/CEUGuidancelntrauterineContraceptionNov07. pdf [Accessed 22 August 2010].

\section{Lost IUD penetrating bladder wall}

I read with interest the letter about uterine perforation with an intrauterine device (IUD) by Vural and colleagues in the July issue of the Journal. ${ }^{1}$ The authors state that they believe their case to be the first report of bladder perforation by an IUD. However, they cite a paper that gives details of six such cases reported during the 1970s! ${ }^{2}$ This classic review by Zakin et al. analyses 356 cases of perforation at multiple sites and goes on to propose mechanisms by which perforation occurs. Perforation of the uterus and through to the bladder or ureter is an uncommon but regularly reported complication of intrauterine device insertion.

There are about 70 cases of perforation involving the urinary tract reported in the literature. ${ }^{3}$ The first report appears to have been of a Lippes loop. ${ }^{4}$ All other types of device are represented, including the Dalkon Shield, ${ }^{5}$ copper IUDs including Multiload, ${ }^{6}$ the intrauterine system (IUS) 7 and GyneFix. ${ }^{8}$
Some of these reports mention more than one occurrence. All reports concern perforation that resulted in an IUD located within the urinary tract. Some of these reports, especially those written by urologists, refer to spontaneous migration of the device. Vural et al. think it is a matter of debate how devices end up in the urinary tract. Consensus opinion is, however, that spontaneous migration does not happen; the device is in fact forced through the uterine wall at the time of insertion. ${ }^{9-11}$ The only exceptions are rare cases of partial perforation mentioned by Zakin $e t$ al. ${ }^{2}$

Sam Rowlands, MD, FFSRH

Honorary Associate Professor, Warwick

Medical School, Coventry, UK

E-mail:sam.rowlands@warwick.ac.uk

References

Vural M, Toy H, Camuzcuoglu H, Sezgin B. Lost IUD penetrating bladder wall [Letter]. J Fam Plann Reprod penelrating bladder wall [Let

2 Zakin D, Stern WZ, Rosenblatt R. Complete and partial perforation and embedding following insertion partial pertoration and embedding following insertion mechanism, incidence, and missing string. Obstet Gynecol Surv 1981; 36: 335-353. Istanbulluoglu MO, Ozcimen EE, Ozturk B, Uckuyu A, intrauterine Govice. Bladder perforation related to 207-209.

207-209.

Rubin A. Complications due to Lippes loop. Report of a death and other complications seen over an 18Gynaecol 1972; 10: 45 .

5 Neutz E, Silber A, Merendino VJ. Dalkon Shield perforation of the uterus and urinary bladder with calculus formation: case report. Am J Obstet Gynecol 1978; 130: 848.

6 Kriplani A, Banerjee N, Hemal AK, Takkar D. Partial perforation of the bladder by Multiload. Aust $N Z$ Obstet Gynaecol 1999; 39: 133-135.

Khan ZA, Khan SA, Williams A, Mobb GE. Intravesica migration of levonorgestrel-releasing intrauterin system (LNG-IUS) with calculus formation. Eur system (LNG-IUS) with calculus formation. Eur

8 Eskandar OS, Eckford SD. Intravesical migration of GyneFix intrauterine device. J Fam Plann Reprod Health Care 2003; 29: 237-238.

9 Shearman RP. Contraception and sterilization. In Whitfield CR (ed.), Dewhurst's Textbook of Obstetrics and Gynaecology for Postgraduates (4th edn). Oxford, UK: Blackwell, 1986; 568 .

10 Rowlands S, Hampton N. Intrauterine contraception. In: Kubba A, Sanfilippo J, Hampton N (eds), Contraception and Office Gynecology: Choices in Reproductive Healthcare. London, UK: W B Saunders, 1999; 93-112

11 Grimes DA Intrauterine devices. In: Hatcher RA Trussell J, Nelson AL, Cates W, Stewart FH, Kowal D (eds), Contraceptive Technology (19th edn). New York, NY: Ardent Media, 2007; 117-143.

\section{Two cases of broken Implanon ${ }^{\circledR}$}

We thought Journal readers might be interested to hear about two cases of broken Implanon ${ }^{\circledR}$ that we came across in our practice recently.

Between October 2003 and December 2009 we fitted 465 Implanon and removed 254 . We have always reassured clients that the implant cannot break as it is very flexible, and we showed clients when we removed an implant how it could be bent and stretched without breaking. We cannot, however, state this with certainty any more after having removed two broken implants within a 7-week period.

The first client, an 18-year-old, had only used condoms previously. She had an Implanon fitted on 20 May 2009. She was seen on 1 July 2009 as she was worried that the implant had broken. It was situated subdermally in her left inner upper arm over the triceps and we reassured her it felt intact but bent. She was otherwise happy with the implant. She came back to the clinic on 12 December 2009 and asked for the implant to be removed as she had been bleeding since the end of July with only 3 or 4 non-bleeding days. She declined a trial with oral contraceptive pills and stated she wanted to use condoms in the future, so we proceeded to remove her implant using the 'pop-out' technique. It was a successful, easy removal but we were really surprised when we saw the implant. It was nearly broken in half and was

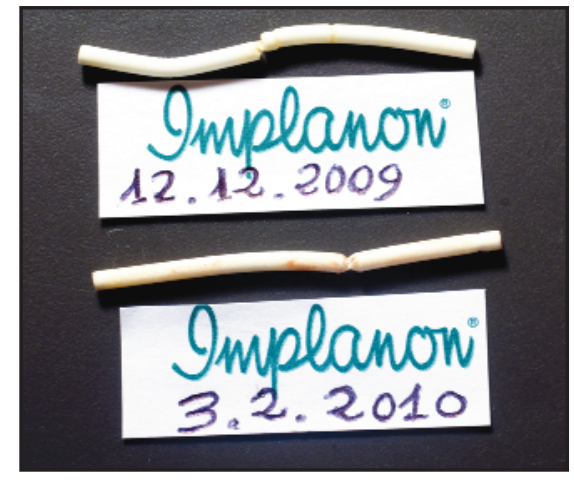

Figure 1 Photograph showing

only joined by the fine sheath. It had two further breaks and was also bent (Figure 1). On questioning, the client admitted that she often played with the implant.

The second client was 22 years old. She had used condoms previously when one split and she became pregnant. Her implant was fitted after a termination of pregnancy in April 2007. She was happy with her implant initially but later she experienced irregular prolonged bleeding and so she was 'topped up' with the combined oral contraceptive pill, which controlled the bleeding as long as she took the pills regularly. The client was seen in clinic on 3 February 2010 after she had decided to have her implant removed and continue taking the combined pill. The implant was subdermally situated in her left inner upper arm over the triceps and felt intact. It was removed easily by means of the 'pop-out' technique. This implant was also broken into two halves (Figure 1), and once again the client agreed that she played with her implant a lot.

We have been experimenting with the implants we removed and feel that the only explanation could be a repetitive bending action that weakens the structure of the rod. We tried bending one of these implants around 200 times and only managed to bend it not break it.

We could find only one published article referring to another case of a broken Implanon. ${ }^{1}$ In this case and in our two cases there was irregular bleeding. As Pickard and Bacon suggested in their article, the broken implant could result in an inadequate release of the etonogestrel and thus be responsible for the irregular bleeding. These authors recommended that if a broken implant is suspected of causing irregular bleeding then it should be replaced. ${ }^{1}$

We spoke with a doctor from the pharmaceutical company concerned and were unable to obtain any more information about similar cases; however, it seems that the hypothesis of Pickard and Bacon could be true. We could try to confirm this hypothesis by checking blood levels of etonogestrel, however this is an expensive test.

María Dolores Tomás-Tello, LMS(Spain), DFSRH Doctor in Contraception and Sexual Health, BACHS, Bradford and Airedale tPCT, Bradford, UK.E-mail:dtomas@doctors.org.uk

Gill Hodgson, MRCGP, DFSRH

GP Specialist in Contraception and Sexual Health, BACHS, Bradford and Airedale tPCT, Bradford, $U K$.

E-mail: Gill.Hodgson@bradford.nhs.uk

Acknowledgement

This letter is printed with the permission of the patients concerned.

Reference

Pickard S, Bacon L. Persistent vaginal bleeding in a patient with a broken Implanon ${ }^{\circledR}$. J Fam Plann Reprod patient with a broken Implanon 